\title{
Plastic identification based on molecular and elemental information from laser induced breakdown spectra: a comparison of plasma conditions in view of efficient sorting
}

\author{
Sophie Barbier ${ }^{\mathrm{a}}$, Sébastien Perrier ${ }^{\mathrm{a}}$, Pierre Freyermuth ${ }^{\mathrm{b}}$, Didier Perrin ${ }^{\mathrm{c}}$, Benjamin Gallard ${ }^{\mathrm{c}}$, Nicole Gilon ${ }^{\mathrm{a}, *}$ \\ a Institut des Sciences Analytiques, UMR 5280, CNRS, Université de Lyon, Villeurbanne, France \\ b EFS Technologies, Montagny, France \\ c Centre des Matériaux de Grande Diffusion, Ecole des Mines d'Alès, Alès, France
}

\begin{abstract}
A B S T R A C T
This work is dedicated to a comparison of plasma conditions for the accurate determination of some elements: $\mathrm{Br}, \mathrm{Cl}, \mathrm{Ca}, \mathrm{P}$ and $\mathrm{Sb}$, in polymers. The comparison of the plasma conditions to sort plastics according to $\mathrm{CN}, \mathrm{C} 2$ and element signals was also investigated. The comparison of a helium atmosphere and an air atmosphere led to improved results using helium as a buffer gas. The improvement is obtained in two areas, it increased the detection of halogens $(\mathrm{Br}, \mathrm{Cl})$ usually employed as flame retardants. It was also found to significantly improve the discrimination based on simple calculations of $\mathrm{C} 2 / \mathrm{He}$ and $\mathrm{CN} / \mathrm{He}$ ratios. Best conditions were based on a laser emitting at $266 \mathrm{~nm}$, with a low $6 \mathrm{~mJ}$ energy focalized on a $50 \mu \mathrm{m}$ spot and the helium buffer gas. A plot of $\mathrm{C} 2 / \mathrm{He}$ against $\mathrm{CN} / \mathrm{He}$ was efficient to identify the four groups of plastics employed in this study: polystyrene, polypropylene, acrylonitryle-butadiene-styrene and acrylonitrylebutadiene-styrene/polycarbonate.
\end{abstract}

Keywords:

LIBS

Polymer sorting

Element determination

Laser induced plasma conditions

\section{Introduction}

The determination of the elemental composition of polymers and plastics is a topic of interest to improve waste management. Recycling consumer goods requires an efficient waste sorting to remove potentially toxic plastics from the recycling process, several strategies have been studied in the past decades [1,2]. The stage of sorting is performed mainly using vibrational spectroscopy including infrared and Raman spectroscopy. It is also a current issue of laser induced breakdown spectroscopy (LIBS). If LIBS remained long a technique strictly dedicated to the determination of the inorganic elements, some works deal now with the determination of organics employing the rich LIBS spectra [3-6].

Different emissions, including elementary and molecular information, are often combined to perform an efficient plastic sorting. Due to the particular composition of plastic additives [6], the detection of both flame retardants $(\mathrm{Br}, \mathrm{Cl} \ldots)$ and toxic metals involved in pigments $(\mathrm{Pb}, \mathrm{Cd}, \mathrm{Hg} \mathrm{...)}$ ) is required. In addition, as the visible region of the spectrum is dominated by carbon and molecular emission, the identification of certain elements such as $\mathrm{Zn}$ or $\mathrm{S}$ is made through unusual low UV wavelength. Thus, Jasik [7] employed a laser-induced breakdown spectroscopy in the vacuum ultraviolet range (VUV, $\lambda$ below $200 \mathrm{~nm}$ ) for the detection of trace elements in polyethylene

\footnotetext{
* Corresponding author.

E-mail address: gilon@univ-lyon1.fr (N. Gilon).
}

(PE) that is difficult to detect in the UV/VIS range. For effective laser ablation of $\mathrm{PE}$, they employed an excimer $\mathrm{F}_{2}$ laser (wavelength $\lambda=$ $157 \mathrm{~nm}$ ) with a high pulse energy, of up to $50 \mathrm{~mJ}$, they obtained a limit of detection (LOD) of $50 \mu \mathrm{g} \mathrm{g}^{-1}$ for sulfur and $215 \mu \mathrm{g} \mathrm{g}^{-1}$ for zinc, respectively, in polymer reference materials.

Bromine, used as a flame retardant in thermoplast is also one of the difficult-to-detect elements. A comparison of LIBS analytical criteria based on two Br lines: Br I 827.244 nm and Br I $130.991 \mathrm{~nm}$, showed that the detection limit could be improved by a factor of three when using the low UV Br line [8]. To avoid oxygen, the sample is placed in an argon flushed cell and a vacuum monochromator is employed. An improved detection limit is also obtained using double pulse LIBS, this method was described for the detection of heavy metals $(\mathrm{Cd}, \mathrm{Hg}, \mathrm{Pb})$ in the low $300-1100 \mu \mathrm{g} \mathrm{g}^{-1}$ range [9].

With the benefit of rich spectral information, the need for discrimination between samples has also led to an abundant chemometric literature. The high amount of information provided by an LIBS spectra is efficiently simplified using Principal Component Analysis (PCA), it allows to classify plastics or to simply identify outliers [10]. Simple ratios determinations were also employed [6,11]. Independent Modeling of Class Analogy (SIMCA) was also compared to linear correlation and PCA to discriminate different organic samples [12]. A complete analysis of many plastics: polyethylene (PE), polystyrene (PS), polypropylene (PP), and polyethylene terephthalate (PET), was made using hierarchical cluster analysis, the mentioned polymers could then be classified into two clusters and were further separated [13]. Methods of normalized 
coordinates, linear and rank correlation were applied to identify polymers with a very similar chemical composition [14]. Best results were obtained using the linear correlation method. To control the occurrence of toxic elements in toys, Discriminant analysis, Soft independent modeling and K-Nearest Neighbor (KNN) were also compared [15]. The classification models were established and eleven organic materials including: PS, PP, PET, HDPE, LDPE (high- and low density polyethylene), PVC (polyvinyl chloride), and PTFE (polytetrafluoroethene) were studied. The KNN method gave the best results with a correct prediction of 95\% for $\mathrm{Cd}$ occurrence in toy sample, and $100 \%$ for $\mathrm{Cr}$ and $\mathrm{Pb}[15,16]$. The work of Boueri [17] demonstrates a successful treatment of LIBS spectra with neural network for the identification of PP, PVC, PE, PTFE, POM (polyoxymethylene), PA (polyamide or nylon), PC (polycarbonate) and PMMA (poly-methylmethacrylate). The identification rates were ranging between 81 and 100\% [17]. Using a careful temporal signal optimization Gregoire [18] also compared different statistical treatments of polymer spectra: line ratios, PCA and PLS (Partial least square). The discrimination was possible, even between polyethylene and polypropylene using this protocol [18].

This work is dedicated to select criteria based on LIBS spectra for plastic sorting. A comparison of plasma conditions for the accurate determination of some elements present in polymers as well as the validity of molecular information for plastic nature identification was made. A comparison of elements response in the different polymers was established. The careful evaluation of fluence and buffer gas nature was also discussed in view of lowering the detection limits for chlorine and bromine flame retardants. The plasma conditions were also investigated to establish best conditions to use $\mathrm{CN} / \mathrm{He}$ and $\mathrm{C} 2 / \mathrm{He}$ ratio intensities to efficiently discriminate plastics investigated in our work: polystyrene, polypropylene, acrylonitrile, 1,3-butadiene-styrene (ABS) and a mixture of ABS with polycarbonate.

\section{Experimental}

\subsection{Materials}

Tested reference plastics were containing five different additives into four thermoplastic polymers used for electrical and electronic applications in controlled concentrations. The nature of each polymer and concentration of the additives are presented in Table 1.

Commercial grade ABS (Terluran GP22), HiPS (Escrimo KG2), ABS-PC (C2800) and PP (3400MA1) polymers were purchased from BASF (ABS and HiPS), Sabic and Appryl respectively. In the following text these polymers will be referred as A for ABS, $\mathrm{H}$ for HiPS, $\mathrm{C}$ for ABS-PC and P for PP.

The commercial additives employed were calcium carbonate for calcium addition (Socal), chloride flame retardant as 1,2,3,4,7,8,9,10,13, 13,14,14-dodecachloro-1,4,4a,5,6,6a,7,10,10a,11,12,12a-dodecahydro1,4,7,10-dimethanodibenzo[a,e]cyclooctene (Dechlorane C25 Plus), phosphorus flame retardant as ammonium polyphosphate (Clariant AP423), bromide flame retardants as tetrabromobisphenol A (Aldrich) and as decabromodiphenylether in synergy with antimony oxide (FR1203). For each of the additives, four to five plastic pieces were available; these were containing increasing concentration of the additive from 1 to $20 \% \mathrm{w} / \mathrm{w}$. For each of the concentrations, again four samples were available.

\subsection{Extrusion and injection molding procedures for reference formulations}

A CLEXTRAL BC 21 twin-screw co-rotating extruder $(L=1200 \mathrm{~mm}$, $L / D=48$ ) was used for the introduction of additives into thermoplastic matrices. The extrusion was done at an adapted temperature of each formulation and with a rotation speed of $4.2 \mathrm{~Hz}$ using a 27 element screw profile with the rate of $5 \mathrm{~kg} \mathrm{~h}^{-1}$. After exiting the extruder, the melted compounds were passed through a water bath and then chipped into pellet form. As in the extrusion step, the composites were dried for $12 \mathrm{~h}$ at $80{ }^{\circ} \mathrm{C}$ under vacuum prior to injection molding in order that there was a polymer chain relaxation. After extrusion, $100 \times 100 \mathrm{~mm}$ plates and pastilles of diameters 10,20 and $30 \mathrm{~mm}$ respectively were injection molded using a SANDRETTO AT injection molding device. All the materials were $4 \mathrm{~mm}$ thick.

\subsection{Instrument}

The LIBS system was a commercial MobiLIBS (IVEA, France)[19]. The Nd:YAG laser (Quantel Brio) was employed at $266 \mathrm{~nm}$ and $532 \mathrm{~nm}$ delivering a maximum of $6 \mathrm{~mJ}$ and $33 \mathrm{~mJ} /$ pulse respectively. Pulse duration was $3 \mathrm{~ns}$ and a fixed frequency of $20 \mathrm{~Hz}$. Spot diameters were measured at $50 \mu \mathrm{m}$ for the $266 \mathrm{~nm}$ and $120 \mu \mathrm{m}$ for the $532 \mathrm{~nm}$. As the focusing system and the pulse duration are fixed on this system, the only parameter likely to change the irradiance was the energy selected by the operator. The light emitted by the resulting plasma was collected by a lens and an optical fiber and sent to an Andor echelle spectrometer (Mechelle 5000). This spectrometer has a resolving power of $\lambda / \Delta \lambda=5000$. The diffracted light was then collected by an intensified charge coupled device (ICCD) camera (Andor iStar). The spectral range of this system was 200-975 nm. The Analibs ${ }^{\mathrm{TM}}$ software controlled the detection and laser firing. Argon (5.0 grade) and Helium (6.0 grade) were purchased from Linde gas.

The spectra were accumulated from 60 laser shots, a moderate number of laser shots was preferred in order to reduce the potential degradation of the polymer due to heat diffusion over the surface during measurement. All parameters: number of pulses, fluence, delay time, and integration time gate were optimized using classical univariate approach.

Table 1

Formulations of reference samples.

\begin{tabular}{|c|c|c|c|c|c|}
\hline \multirow{3}{*}{$\begin{array}{l}\text { Matrix reference: } \\
\text { polymer containing }\end{array}$} & \multicolumn{5}{|c|}{ Additives and concentration range } \\
\hline & \multirow{2}{*}{$\begin{array}{l}\text { Br (bromide flame retardant) } \\
\text { (1): TBBA } \\
(\%) \mathrm{m} / \mathrm{m}\end{array}$} & \multirow{2}{*}{$\begin{array}{l}\mathrm{Cl} \text { (chloride flame } \\
\text { retardant) } \\
(\%) \mathrm{m} / \mathrm{m}\end{array}$} & \multirow{2}{*}{$\begin{array}{l}\text { Ca (calcite) } \\
(\%) \mathrm{m} / \mathrm{m}\end{array}$} & \multirow{2}{*}{$\begin{array}{l}\mathrm{P} \text { (phosphorus } \\
\text { flame retardant) } \\
(\%) \mathrm{m} / \mathrm{m}\end{array}$} & \multirow{2}{*}{$\begin{array}{l}\mathrm{Br} \text { (bromide flame retardant) (2):TBBA } \\
(73.3 \% \mathrm{~mol})+\mathrm{Sb}_{2} \mathrm{O}_{3}(26.7 \% \mathrm{~mol}) \\
(\%) \mathrm{m} / \mathrm{m}\end{array}$} \\
\hline & & & & & \\
\hline $\begin{array}{l}\text { ABS1 Terluran GP22: } \\
\text { acrylonitrile, 1,3-butadiene and styrene (A) }\end{array}$ & $1-20$ & $1-20$ & $1-20$ & $1-12.5$ & $1-11$ \\
\hline $\begin{array}{l}\text { ABS-PC Sabic C2800: acrylonitrile, 1,3-butadiene, } \\
\text { styrene and polycarbonate (C) }\end{array}$ & $1-20$ & $1-20$ & $1-20$ & $1-12.5$ & $1-11$ \\
\hline $\begin{array}{l}\text { PP Apryl } 3400 \text { MA1: } \\
\text { polypropylene (P) }\end{array}$ & $1-20$ & $1-20$ & $1-20$ & $1-12.5$ & $1-11$ \\
\hline $\begin{array}{l}\text { HiPS Escrimo KG2: } \\
\text { polystyrene }(\mathrm{H})\end{array}$ & $1-20$ & $1-20$ & $1-20$ & $1-12.5$ & $1-11$ \\
\hline
\end{tabular}




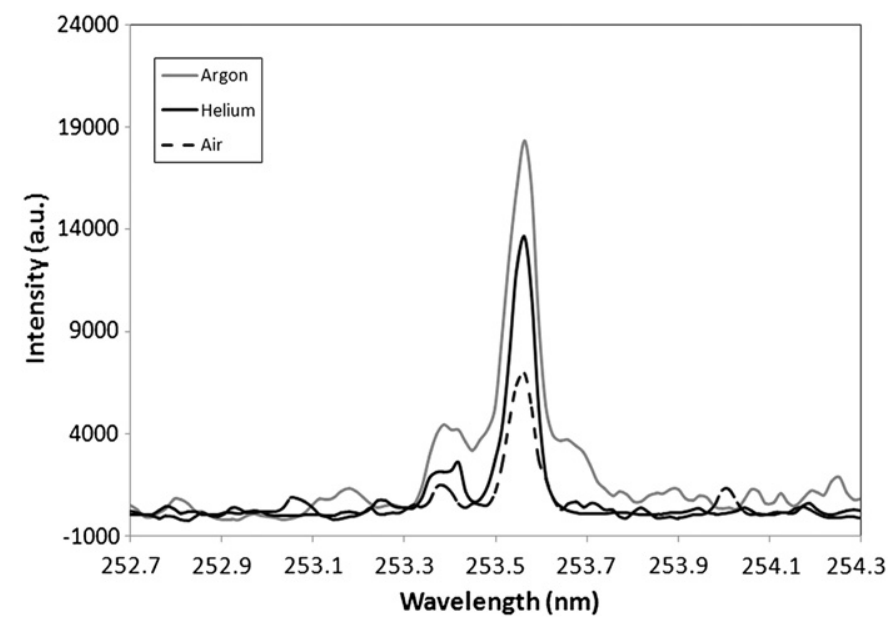

Fig. 1. Spectra of P I $253.560 \mathrm{~nm}$ obtained under helium $\left(1 \mathrm{~L} \mathrm{~min}^{-1}\right)$, Argon $\left(0.2 \mathrm{~L} \mathrm{~min}^{-1}\right)$ and air atmosphere. Measurement conditions: laser $532 \mathrm{~nm}, 12 \mathrm{~mJ}$, delay time $300 \mathrm{~ns}$ and integration time gate $1.5 \mu \mathrm{s}$.

\section{Results and discussion}

Optimization of working parameters was carried out to detect and to quantify easily the elements employed as plastic additives such as $\mathrm{Br}, \mathrm{Cl}, \mathrm{Sb}, \mathrm{P}$ and $\mathrm{Ca}$.

The first two being difficult to detect, even in LIBS spectroscopy, as available lines correspond to high energy level transitions and low VUV lines (Cl I $134.344 \mathrm{~nm}$ ) or near infrared lines ( $\mathrm{Br}$ I $827.244 \mathrm{~nm}$, $\mathrm{Cl}$ I $837.594 \mathrm{~nm}$ ). Phosphor and Antimony are more easily detected in laser induced plasmas, and opposite to the other elements the calcium lines are numerous, sensitive and often self-reversed. Using our system, the selection of working conditions was made in terms of gas nature and flow rate, then laser energy and wavelength. In LIBS spectroscopy, an argon atmosphere is often employed to improve signal, helium [20-22] is also advised to detect halogens at trace level. A comparison of spectra obtained in helium, argon and air atmosphere was made (Fig. 1). Signal was higher under an argon atmosphere for phosphorus. Even if a better sensitivity is provided for some lines, as the $\mathrm{Br}$ I $827.244 \mathrm{~nm}$ was interfered by an argon line, this gas is not adapted for our study. Furthermore, the helium buffer provides also a factor 2 improvement in line intensities when compared to air, similar improvement was also obtained for chlorine and antimony lines. Additionally, as it can be seen from Fig. 1 the line shape of the phosphorus line was improved in air or helium when compared to argon and background in helium buffer was significantly

Table 2

Calculated detection limits as a function of energy and fluence. Measurement conditions were: pulse duration $3 \mathrm{~ns}, \lambda=532 \mathrm{~nm}$, delay time $300 \mathrm{~ns}$, integration time gate $10 \mu \mathrm{s}$ and helium flow rate from 0.2 to $1.4 \mathrm{~L} \mathrm{~min}^{-1}$. Measurements were performed using the Br I $827.244 \mathrm{~nm}$ line and the Sb I $259.805 \mathrm{~nm}$ line.

\begin{tabular}{|c|c|c|c|c|c|}
\hline & & & $\mathrm{Sb}$ & $\mathrm{Br}$ & $\mathrm{Ca}$ \\
\hline $\begin{array}{l}\text { Energy } \\
(\mathrm{mJ})\end{array}$ & $\begin{array}{l}\text { Fluence } \\
\left(\mathrm{J} \mathrm{cm}^{-2}\right)\end{array}$ & $\begin{array}{l}\mathrm{He} \\
\left(\mathrm{L} \mathrm{min}^{-1}\right)\end{array}$ & $\begin{array}{l}\text { LOD } \\
(\% \mathrm{w} / \mathrm{w})\end{array}$ & $\begin{array}{l}\text { LOD } \\
(\% \mathrm{w} / \mathrm{w})\end{array}$ & $\begin{array}{l}\text { LOD } \\
(\% \mathrm{w} / \mathrm{w})\end{array}$ \\
\hline & 100 & 0.2 & 0.081 & 1.7 & 0.69 \\
\hline \multirow[t]{4}{*}{12} & & 0.6 & 0.065 & 1.0 & 0.32 \\
\hline & & 1 & 0.042 & 0.8 & 0.24 \\
\hline & & 1.4 & 0.069 & 0.9 & 0.36 \\
\hline & 164 & 0.2 & 0.065 & 1.8 & 0.27 \\
\hline \multirow[t]{4}{*}{20} & & 0.6 & 0.064 & 1.5 & 0.31 \\
\hline & & 1 & 0.071 & 1.0 & 0.28 \\
\hline & & 1.4 & 0.066 & 0.9 & 0.21 \\
\hline & 270 & 0.2 & 0.069 & 1.4 & 0.25 \\
\hline \multirow[t]{3}{*}{33} & & 0.6 & 0.068 & 1.5 & 0.14 \\
\hline & & 1 & 0.064 & 1.1 & - \\
\hline & & 1.4 & 0.057 & 1.0 & 0.19 \\
\hline
\end{tabular}

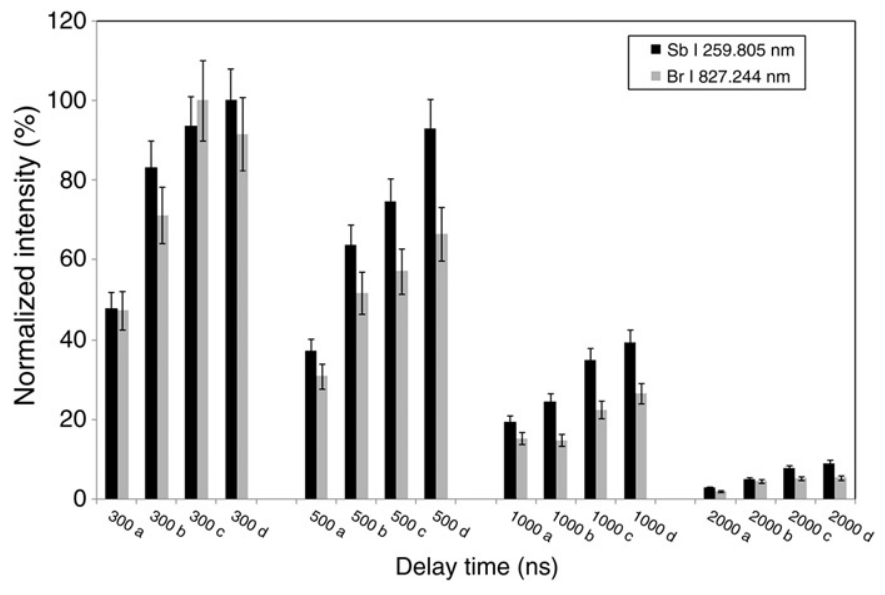

Fig. 2. Net signal of Sb I $259.805 \mathrm{~nm}$ (black) and $\mathrm{Br}$ (I) $827.244 \mathrm{~nm}$ (gray) as a function of delay time (300 ns to $2000 \mathrm{~ns}$ ) and integration time gate (a: $0.5 \mu \mathrm{s}$, b: $1 \mu \mathrm{s}, \mathrm{c}: 1.5 \mu \mathrm{s}$ and d: $10 \mu \mathrm{s}$ ). Signal (\%) normalized to the maximum value (measurement conditions: helium $1 \mathrm{~L} \mathrm{~min}{ }^{-1}, 532 \mathrm{~nm}$ Laser). The error bars correspond to a $95 \%$ confidence interval of the sample signal measured in five replicates.

reduced in comparison with air or argon and thus the uncertainty of the background was reduced as well. A comparison of helium, and air was made to evaluate benefit on signals and limits of detection ( $L O D=3 \sigma / b_{1}$; where $\sigma$ is the noise and $b_{1}$ is the line sensitivity). Different helium flow rates from $0.2 \mathrm{~L} \mathrm{~min}^{-1}$ to $1.4 \mathrm{~L} \mathrm{~min}^{-1}$ were evaluated (Table 2). Helium has the advantage, of a higher ionization
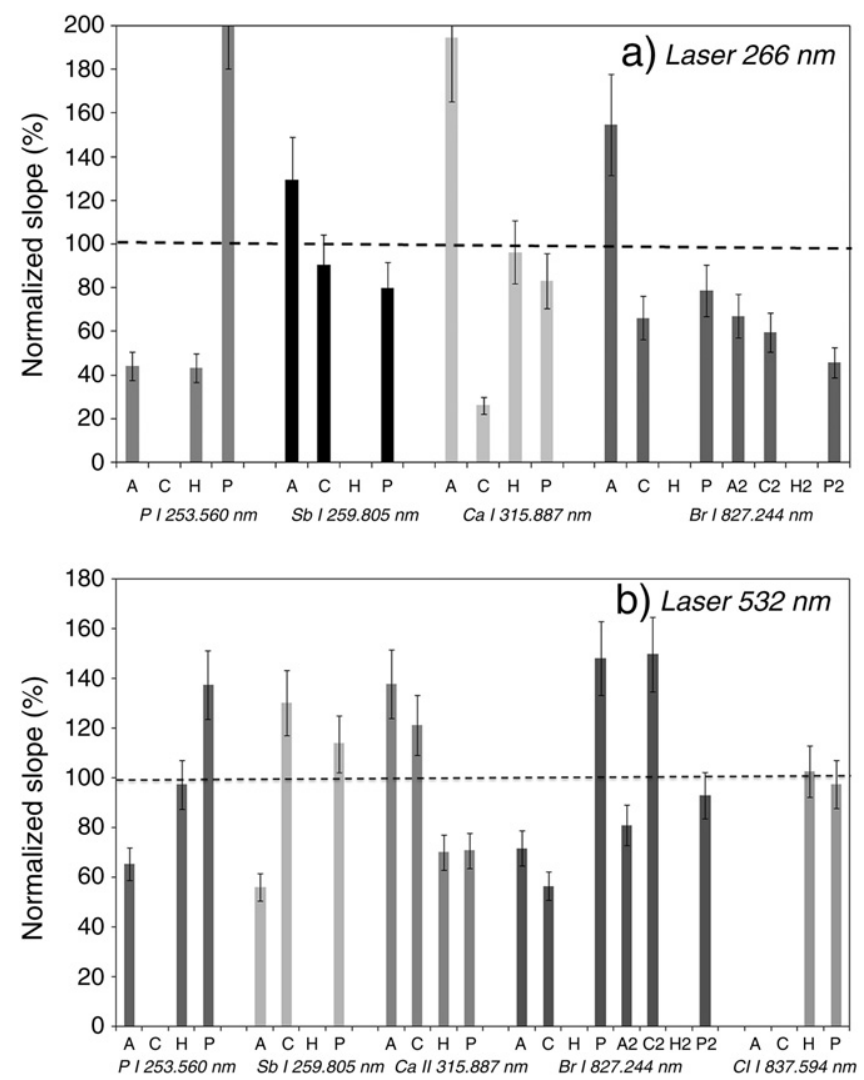

Fig. 3. Slopes $\left(\mathrm{b}_{1}\right)$ of the elements $\mathrm{Sb}, \mathrm{P}, \mathrm{Ca}, \mathrm{Br}$ and $\mathrm{Cl}$ as a function of the plastic nature $(\mathrm{A}, \mathrm{H}, \mathrm{C}, \mathrm{P})$. Values are normalized to the maximum slope. The error bars represent the uncertainty of the calibration slope $\left(s_{b_{1}}\right)$ at a $95 \%$ confidence level. Number of standards was at least 4 and number of replicates for each standard was 4 . (a) Laser $266 \mathrm{~nm}$, helium buffer gas, (b) $532 \mathrm{~nm}$ laser, helium buffer gas. 
Table 3

Concentration (\% $\mathrm{w} / \mathrm{w})$ estimation in plastics A, P and C. Measurements were performed using the $\mathrm{Br}$ I $827.244 \mathrm{~nm}$ line and the Sb I $259.805 \mathrm{~nm}$ line. Uncertainty is reported at a $95 \%$ confidence level from 4 repetition of the determination.

\begin{tabular}{|c|c|c|c|c|c|c|}
\hline \multicolumn{3}{|c|}{$\begin{array}{l}\text { Prepared concentrations } \\
\operatorname{RSD}_{\mathrm{n}}=4(\%)\end{array}$} & \multicolumn{4}{|c|}{$\begin{array}{l}\text { Determined concentrations } \\
\mathrm{RSD}_{\mathrm{n}=4}(\%)\end{array}$} \\
\hline & $\mathrm{Sb}$ & $\mathrm{Br}$ & $\mathrm{Sb}(1)$ & $\mathrm{Br}(1)$ & $\mathrm{Sb}(2)$ & $\operatorname{Br}(2)$ \\
\hline $\mathrm{A}(\mathrm{Br}) 1$ & & 1.0 & 0.1 & $2.1(22)$ & 0.3 & $0.4(18)$ \\
\hline $\mathrm{A}(\mathrm{Br}) 2$ & & 5.0 & 0.0 & $3.6(6)$ & 0.3 & $2.1(13)$ \\
\hline$A(B r) 3$ & & 10.0 & 0.0 & $8.7(1)$ & 0.3 & $6.2(6)$ \\
\hline $\mathrm{P}(\mathrm{Br}) 1$ & & 1.0 & 0.0 & $0.5(30)$ & 0.4 & 1.0 (19) \\
\hline $\mathrm{P}(\mathrm{Br}) 2$ & & 5.0 & -0.1 & $5.4(5)$ & 0.4 & $4.7(5)$ \\
\hline $\mathrm{P}(\mathrm{Br}) 3$ & & 10.0 & -0.1 & $5.3(6)$ & 0.4 & $10.8(8)$ \\
\hline $\mathrm{P}(\mathrm{Br}) 4$ & & 20.0 & -0.1 & $20.2(1)$ & 0.4 & $20.1(3)$ \\
\hline $\mathrm{C}(\mathrm{Br}) 1$ & & 1.0 & 0.0 & $3.7(11)$ & 0.5 & $1.6(16)$ \\
\hline $\mathrm{C}(\mathrm{Br}) 2$ & & 5.0 & 0.0 & $7.1(3)$ & 1.7 & $5.9(7)$ \\
\hline $\mathrm{C}(\mathrm{Br}) 3$ & & 10.0 & 0.0 & $9.6(2)$ & 0.4 & $10.0(0.5)$ \\
\hline $\mathrm{A}(\mathrm{Sb}, \mathrm{Br}) 1$ & 1.1 & 1 & 0.4 (19) & 2.8 (19) & $1.4(14)$ & $0.8(23)$ \\
\hline $\mathrm{A}(\mathrm{Sb}, \mathrm{Br}) 2$ & 5.6 & 5 & $7.8(5)$ & $6.7(4)$ & $4.5(4)$ & $4.7(14)$ \\
\hline $\mathrm{A}(\mathrm{Sb}, \mathrm{Br}) 3$ & 9.0 & 8 & $12.9(3)$ & $8.7(3)$ & $8.6(2)$ & $7.8(8)$ \\
\hline $\mathrm{A}(\mathrm{Sb}, \mathrm{Br}) 4$ & 12.3 & 11 & $17.0(2)$ & $12.7(2)$ & $14.0(8)$ & $10.9(4)$ \\
\hline $\mathrm{P}(\mathrm{Sb}, \mathrm{Br}) 1$ & 1.1 & 1 & $2.7(9)$ & $1.9(16)$ & $1.4(20)$ & $0.8(6)$ \\
\hline $\mathrm{P}(\mathrm{Sb}, \mathrm{Br}) 2$ & 5.6 & 5 & $4.3(2)$ & $3.3(5)$ & $6.6(6)$ & $6.1(14)$ \\
\hline $\mathrm{P}(\mathrm{Sb}, \mathrm{Br}) 3$ & 9.0 & 8 & $7.8(2)$ & $8.1(2)$ & 9.8 (17) & $9.9(12)$ \\
\hline $\mathrm{P}(\mathrm{Sb}, \mathrm{Br}) 4$ & 12.3 & 11 & $12.4(1)$ & $9.1(2)$ & $13.3(2)$ & $15.2(6)$ \\
\hline $\mathrm{C}(\mathrm{Sb}, \mathrm{Br}) 1$ & 1.1 & 1 & $0.2(13)$ & $2.5(38)$ & $1.0(9)$ & $0.4(14)$ \\
\hline $\mathrm{C}(\mathrm{Sb}, \mathrm{Br}) 2$ & 5.6 & 5 & $5.0(2)$ & $2.0(15)$ & $4.2(13)$ & $5.4(11)$ \\
\hline $\mathrm{C}(\mathrm{Sb}, \mathrm{Br}) 3$ & 9.0 & 8 & $6.8(2)$ & $7.5(3)$ & $10.0(3)$ & $10.5(7)$ \\
\hline $\mathrm{C}(\mathrm{Sb}, \mathrm{Br}) 4$ & 12.3 & 11 & $12.3(1)$ & $11.1(2)$ & $9.3(3)$ & $10.4(0.4)$ \\
\hline
\end{tabular}

(1) Laser $266 \mathrm{~nm}$, helium buffer gas, $6 \mathrm{~mJ} .200 \mathrm{~ns}$ delay time and $3 \mu$ s integration time gate. (2)Laser $532 \mathrm{~nm}$, air atmosphere $33 \mathrm{~mJ}, 300 \mathrm{~ns}$ and $10 \mu$ sintegration time gate.

energy $(23.5 \mathrm{eV})$ that implies more efficient ionization of elements not only with high ionization energy such as $\mathrm{Br}, \mathrm{Cl}$ and $\mathrm{P}$ employed in this study but also: F, I, Hg, S, As, Se ... [23]. As it can be seen, the flow rate effect was moderate and a stable $1 \mathrm{~L} \mathrm{~min}^{-1}$ flow was allowed to fill the ablation cell so that the element signals and signal-to-noise-ratios were stable and optimum.

A second essential parameter in LIBS spectroscopy is the fluence (energy density at the sample surface), the effects of both helium flow rate and fluence are shown on Table 2, with the examples of $\mathrm{Sb}, \mathrm{Ca}$ and $\mathrm{Br}$. The laser energy was moved from 12 to $33 \mathrm{~mJ}$ leading to a fluence ranging from 100 to $270 \mathrm{~J} \mathrm{~cm}^{-2}$. The higher the fluence, the higher the intensity, the improvement factor was 4 for $\mathrm{Ca}$ and $\mathrm{Sb}$ and only 2 for Br but the background increase led to lower signal to noise ratios. In air only the higher fluence allowed to detect $\mathrm{Br}$ with a calculated LOD of $3.6 \% \mathrm{w} / \mathrm{w}$. The optimization of delay time and gate integration time is shown on Fig. 2, the trend obtained is presented only for Sb I $259.805 \mathrm{~nm}$ and Br I $827.244 \mathrm{~nm}$. A short 300 ns delay and a long integration time gate gave best results for most lines, a $10 \mu$ s integration time gate was selected. Similar study was achieved for three plasma conditions (i.e. laser emitting at $266 \mathrm{~nm}$ with helium atmosphere and laser emitting at $532 \mathrm{~nm}$ with air and helium atmosphere) and only the optimal integration gate time was significantly shorter for the $266 \mathrm{~nm}$ laser wavelength as the global emission was shorter.

Plastic sample with different polymers and additives could imply varying efficiency of the laser ablation, and therefore varying properties of the generated plasma and eventually its stoichiometry, from previous works it could be estimated from the rotational temperature and electron density from different spectra that the plasma is different from one matrix to the other $[24,25]$. In this work it was important to evaluate the risk of mis-identification or wrong estimation of the concentration of an element due to the matrix effect. In the experiments, the different polymer matrices $(\mathrm{A}, \mathrm{C}, \mathrm{H}$ or $\mathrm{P}$ ) were provided with 4 or 5 samples containing different concentrations: 1 to $20 \% \mathrm{w} / \mathrm{w}$ depending on the element. For each matrix and element, a plot of the calibration curve: $\mathrm{I}=\mathrm{b}_{0}+\mathrm{b}_{1}[\mathrm{C}]$ gave a slope $\mathrm{b}_{1}$ for each element, $\mathrm{b}_{0}$ is the $y$ intercept, $[C]$ the concentration and I the net intensity. The different slopes were normalized to the mean value, Fig. 3(a, b) exhibits the normalized slopes as a function of the sample matrices $\mathrm{A}, \mathrm{H}, \mathrm{C}$ and P. A departure from $100 \%$ indicates a matrix effect. The data were obtained for $532 \mathrm{~nm}$ in air and helium, and $266 \mathrm{~nm}$ under helium atmosphere, Fig. 3 only represents the results for $532 \mathrm{~nm}$ and $266 \mathrm{~nm}$ in helium. As it can be seen an important matrix effect was observed with slopes varying from $10 \%$ to a factor 2 . A normalization procedure of the net intensities by an internal reference line: either the C I $247.856 \mathrm{~nm}$ or any other carbon or $\mathrm{CN}$ signal could not improve the results as the carbon content vary greatly from one polymer to the other. A mean calibration curve was established from the 3 to 4 slopes obtained in different plastics. An example of the concentrations found for $\mathrm{Br}$ and $\mathrm{Sb}$ is shown on Table 3. The identification of an element is correct in all case, the mis-identification of an element, i. e. present although it is not present, is seldom. This was especially obtained for

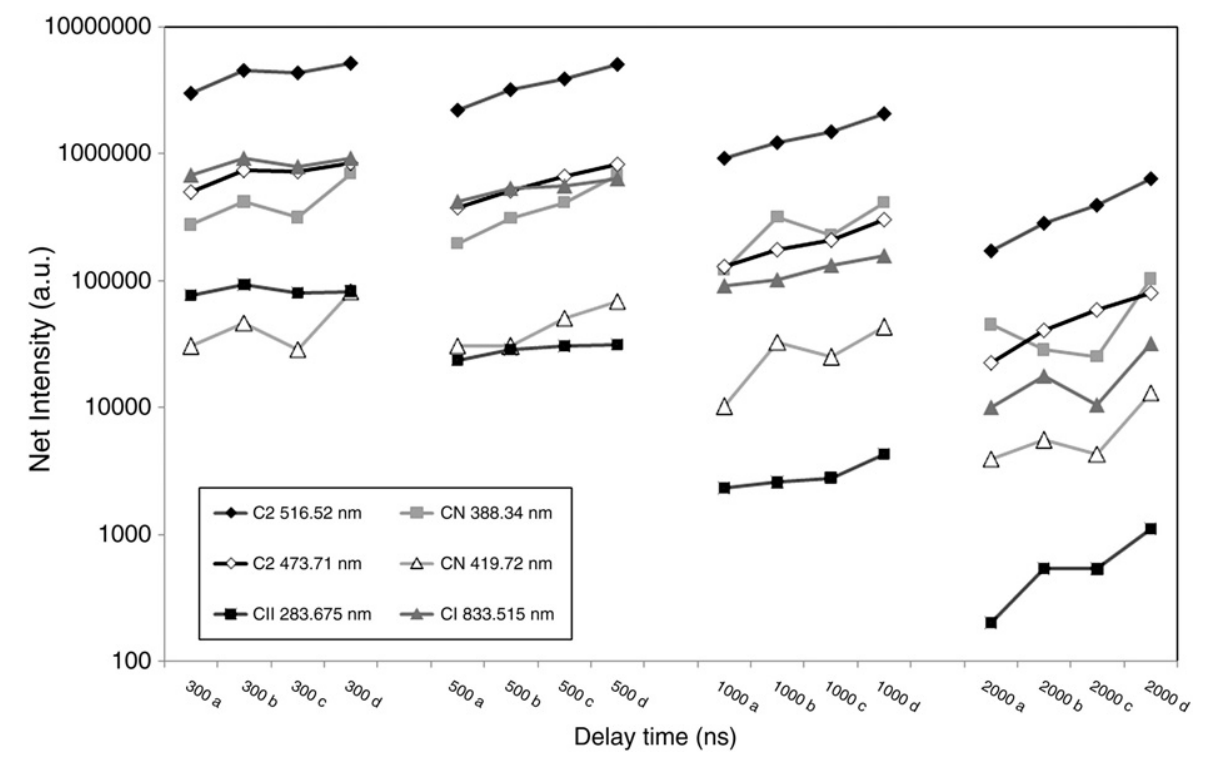

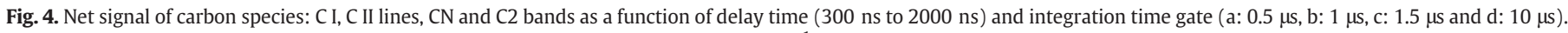

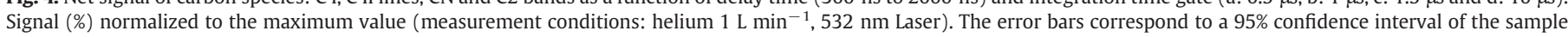
signal measured in five replicates. 
calcium, it must be noticed that calcium could be present as a contamination of the additives employed. In the case of phosphorus, the y intercept of the calibration curves was strongly negative, no matter of the plastic matrix was investigated, and therefore, the $0.5 \% \mathrm{w} / \mathrm{w}$ concentration is not significant. Despite the observed matrix effects and the calculation procedure (mean slope), the trueness was fair and no false identification was obtained. Sb determination was more accurate than that of Br. Using an air atmosphere and a $532 \mathrm{~nm}$ emitting laser (condition 2), the bias is ranging from 5 to $16 \%$ with a mean value of $14 \%$, for the three $\mathrm{Sb}$ containing plastics. Using the same conditions, for the six Br containing plastics, the bias is ranging from 0.5 to $60 \%$ with a mean value of $18 \%$. A factor 2 error was often encountered for the low $1 \% \mathrm{w} / \mathrm{w}$ Br values.

The discrimination of plastics should also be based on molecular information, so that temporal evolution not only of $\mathrm{CN}$ and $\mathrm{C} 2$ bands but also of carbon, helium and hydrogen signals were evaluated to ensure reliable measurements. Using a time integration gate of $0.5 \mu$, $1 \mu \mathrm{s}$ and $10 \mu \mathrm{s}$ and an increasing delay time, the temporal behavior of CN $388.34 \mathrm{~nm}, \mathrm{CN} 419.72$, C2 473.33 and C2 $516.52 \mathrm{~nm}$, C I $247.856 \mathrm{~nm}$ and C I $833.515 \mathrm{~nm}$ were followed together with $\mathrm{CI}$ $283.760 \mathrm{~nm}$. As seen from Fig. 4, a strong intensity decrease is observed for $\mathrm{CI} 283.760 \mathrm{~nm}$, the ionic carbon line is only present at the early stage of plasma. As for element intensities, the $10 \mu$ s delay time allowed to obtain higher signal intensity for the C I, C II, C2 and CN lines. In this experiment, the $\mathrm{CN}$ intensity was only provided by the $\mathrm{N}$ content of the sample as no nitrogen was present in the ablation cell. This means that the nitrogen provided by the polymer molecules was mainly involved in the $\mathrm{CN}$ emission either by direct fragmentation from the organic molecule or by reaction with the carbon in the plasma plume. This result is in good agreement with the experiments carried out by Lucena [26], as they studied organic explosives by LIBS under a helium buffer gas.

Optimized conditions were compared to improve "discriminant emissions". Nitrogen and oxygen signals were not appropriate, even the C I $247.856 \mathrm{~nm}$ and C I $833.515 \mathrm{~nm}$ gave no distinguishable signals between the four plastics. Finally when using the $266 \mathrm{~nm}$ emitting laser and a helium atmosphere, both the helium and hydrogen signals were significantly different between polystyrene and the other plastics (Fig. 5). Using the $532 \mathrm{~nm}$ emission, the discrimination disappeared, the different energy and laser wavelength should be responsible for this behavior. A further study was performed to explain this phenomenon, a correlation analysis was performed using exel ${ }^{\mathrm{TM}}$ statistical tool (Table 4). The correlation between the different molecular signals $(\mathrm{CN}, \mathrm{C} 2)$ was tested and showed that all the $\mathrm{C} 2$ lines gave equivalent information (correlation factors $>0.9$ ) and so did the $\mathrm{CN}$ bands. Furthermore, a good correlation between the $\mathrm{CN}$ and $\mathrm{C} 2$
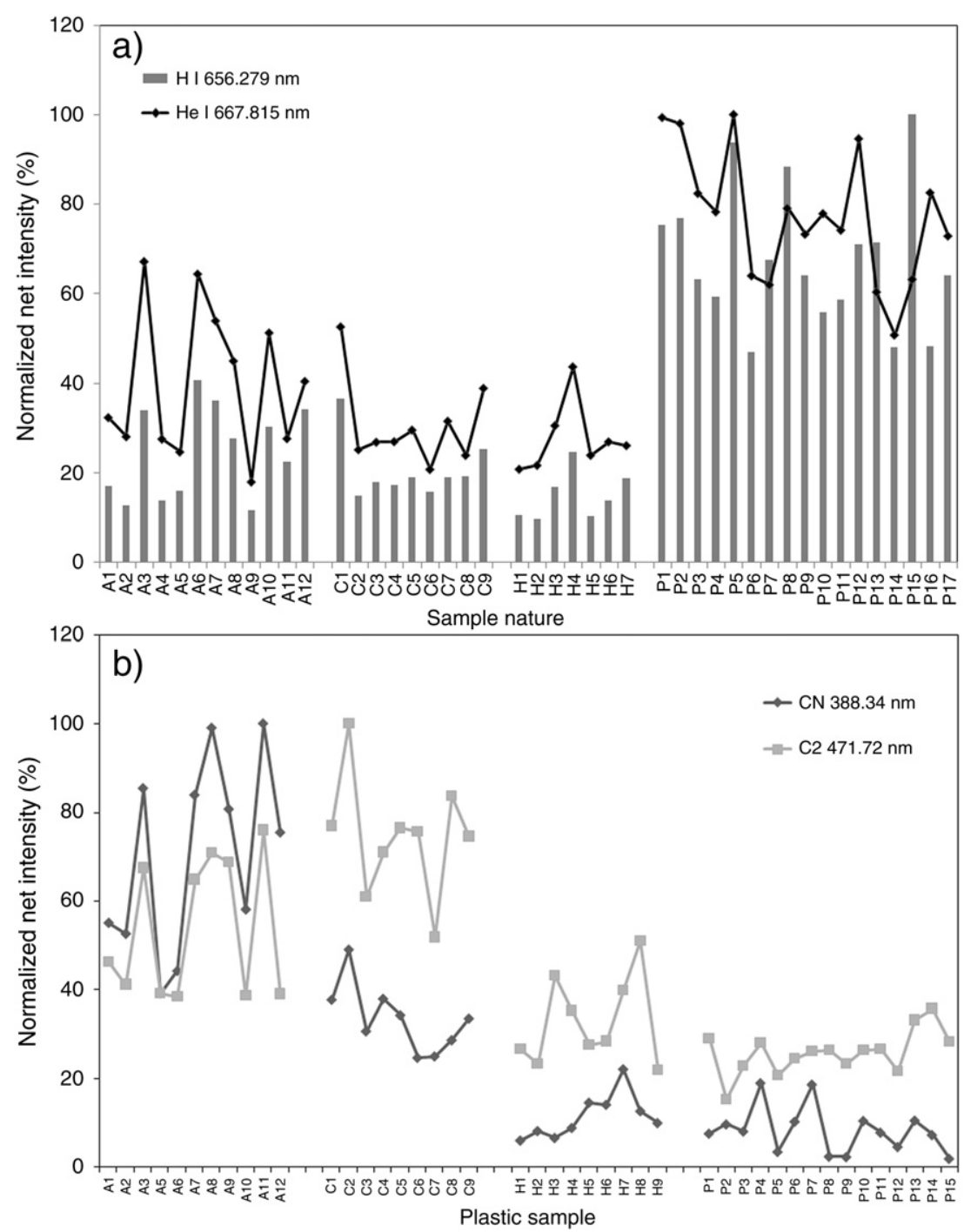

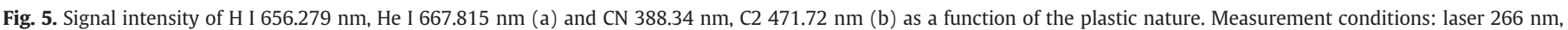
helium $1 \mathrm{~L} \mathrm{~min}{ }^{-1}$, energy $6 \mathrm{~mJ}$, delay time $200 \mathrm{~ns}$, integration time gate $3 \mu$ s. Signals were normalized to the maximum value. 
Table 4

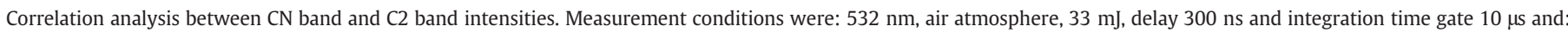
$266 \mathrm{~nm}$, helium atmosphere, $6 \mathrm{~mJ}$, delay $200 \mathrm{~ns}$ and integration time gate $3 \mu \mathrm{s}$. Wavelength (nm) is from reference [27].

\begin{tabular}{|c|c|c|c|c|c|c|c|c|c|c|c|c|c|c|c|c|}
\hline & & $\mathrm{CN}$ & $\mathrm{CN}$ & $\mathrm{CN}$ & $\mathrm{CN}$ & $\mathrm{CN}$ & $\mathrm{CN}$ & $\mathrm{C} 2$ & $\mathrm{C} 2$ & $\mathrm{C} 2$ & $\mathrm{C} 2$ & $\mathrm{C} 2$ & $\mathrm{C} 2$ & $\mathrm{C} 2$ & $\mathrm{C} 2$ & $\mathrm{C} 2$ \\
\hline & & 388.34 & 387.14 & 386.19 & 421.60 & 419.72 & 418.10 & 436.52 & 437.14 & 473.71 & 471.52 & 469.76 & 516.52 & 512.93 & 563.55 & 558.55 \\
\hline \multicolumn{17}{|c|}{ Laser $532 \mathrm{~nm}$. air atmosphere } \\
\hline $\mathrm{CN}$ & 388.34 & 1.0 & & & & & & & & & & & & & & \\
\hline $\mathrm{CN}$ & 387.14 & 1.0 & 1.0 & & & & & & & & & & & & & \\
\hline $\mathrm{CN}$ & 386.19 & 0.9 & 0.9 & 1.0 & & & & & & & & & & & & \\
\hline $\mathrm{CN}$ & 421.60 & 0.9 & 0.9 & 0.9 & 1.0 & & & & & & & & & & & \\
\hline $\mathrm{CN}$ & 419.72 & 1.0 & 1.0 & 0.9 & 0.9 & 1.0 & & & & & & & & & & \\
\hline $\mathrm{CN}$ & 418.10 & 0.4 & 0.4 & 0.4 & 0.6 & 0.4 & 1.0 & & & & & & & & & \\
\hline $\mathrm{C} 2$ & 436.52 & 0.9 & 0.9 & 0.8 & 0.8 & 1.0 & 0.3 & 1.0 & & & & & & & & \\
\hline $\mathrm{C} 2$ & 437.14 & 0.9 & 0.9 & 0.8 & 0.8 & 1.0 & 0.4 & 1.0 & 1.0 & & & & & & & \\
\hline $\mathrm{C} 2$ & 473.71 & 0.9 & 0.9 & 0.8 & 0.8 & 1.0 & 0.4 & 1.0 & 1.0 & 1.0 & & & & & & \\
\hline $\mathrm{C} 2$ & 471.52 & 0.9 & 0.9 & 0.9 & 0.9 & 1.0 & 0.4 & 0.9 & 1.0 & 1.0 & 1.0 & & & & & \\
\hline $\mathrm{C} 2$ & 469.76 & 0.9 & 0.9 & 0.9 & 0.8 & 1.0 & 0.4 & 1.0 & 1.0 & 1.0 & 1.0 & 1.0 & & & & \\
\hline $\mathrm{C} 2$ & 516.52 & 0.9 & 0.9 & 0.8 & 0.8 & 1.0 & 0.4 & 1.0 & 1.0 & 1.0 & 0.9 & 1.0 & 1.0 & & & \\
\hline $\mathrm{C} 2$ & 512.93 & 0.9 & 0.9 & 0.9 & 0.9 & 0.9 & 0.5 & 0.9 & 0.9 & 0.9 & 0.9 & 0.9 & 0.9 & 1.0 & & \\
\hline $\mathrm{C} 2$ & 563.55 & 0.9 & 0.9 & 0.8 & 0.8 & 0.9 & 0.4 & 1.0 & 1.0 & 1.0 & 0.9 & 1.0 & 1.0 & 0.9 & 1.0 & \\
\hline $\mathrm{C} 2$ & 558.55 & 0.9 & 0.9 & 0.9 & 0.8 & 0.9 & 0.3 & 1.0 & 0.9 & 1.0 & 0.9 & 0.9 & 0.9 & 0.9 & 1.0 & 1.0 \\
\hline \multicolumn{17}{|c|}{ Laser $266 \mathrm{~nm}$. helium atmosphere } \\
\hline $\mathrm{CN}$ & 388.34 & 1.0 & & & & & & & & & & & & & & \\
\hline $\mathrm{CN}$ & 387.14 & 1.0 & 1.0 & & & & & & & & & & & & & \\
\hline $\mathrm{CN}$ & 386.19 & 1.0 & 1.0 & 1.0 & & & & & & & & & & & & \\
\hline $\mathrm{CN}$ & 421.60 & 0.5 & 0.5 & 0.6 & 1.0 & & & & & & & & & & & \\
\hline $\mathrm{CN}$ & 419.72 & 1.0 & 1.0 & 1.0 & 0.5 & 1.0 & & & & & & & & & & \\
\hline $\mathrm{CN}$ & 418.10 & 1.0 & 1.0 & 1.0 & 0.6 & 1.0 & 1.0 & & & & & & & & & \\
\hline $\mathrm{C} 2$ & 436.52 & 0.5 & 0.5 & 0.5 & 0.2 & 0.5 & 0.5 & 1.0 & & & & & & & & \\
\hline $\mathrm{C} 2$ & 437.14 & 0.5 & 0.5 & 0.5 & 0.1 & 0.5 & 0.5 & 0.9 & 1.0 & & & & & & & \\
\hline $\mathrm{C} 2$ & 473.71 & 0.6 & 0.6 & 0.5 & 0.2 & 0.6 & 0.6 & 1.0 & 0.9 & 1.0 & & & & & & \\
\hline $\mathrm{C} 2$ & 471.52 & 0.6 & 0.6 & 0.5 & 0.2 & 0.6 & 0.6 & 1.0 & 0.9 & 1.0 & 1.0 & & & & & \\
\hline $\mathrm{C} 2$ & 469.76 & 0.5 & 0.5 & 0.5 & 0.1 & 0.5 & 0.5 & 1.0 & 0.9 & 1.0 & 1.0 & 1.0 & & & & \\
\hline $\mathrm{C} 2$ & 516.52 & 0.6 & 0.6 & 0.5 & 0.2 & 0.6 & 0.6 & 0.9 & 0.9 & 1.0 & 1.0 & 1.0 & 1.0 & & & \\
\hline $\mathrm{C} 2$ & 512.93 & 0.6 & 0.5 & 0.5 & 0.2 & 0.6 & 0.6 & 1.0 & 0.9 & 1.0 & 1.0 & 1.0 & 1.0 & 1.0 & & \\
\hline $\mathrm{C} 2$ & 563.55 & 0.6 & 0.6 & 0.5 & 0.1 & 0.6 & 0.6 & 0.9 & 0.9 & 1.0 & 1.0 & 1.0 & 1.0 & 1.0 & 1.0 & \\
\hline $\mathrm{C} 2$ & 558.55 & 0.5 & 0.5 & 0.5 & 0.2 & 0.5 & 0.5 & 1.0 & 0.9 & 1.0 & 1.0 & 1.0 & 1.0 & 1.0 & 1.0 & 1.0 \\
\hline
\end{tabular}

signals was observed when the LIBS signal was produced in air whereas these were not correlated (correlation factors $<0.6$ ) when a helium atmosphere was employed. From these results it could be concluded that the production of the $\mathrm{CN}$ and $\mathrm{C} 2$ radicals is governed by a specific pathway depending on the nature of the ambient atmosphere. This phenomenon can be employed to better control and improve discriminating information provided by LIBS spectra.

As presented on Fig. 5(b), the CN $388.34 \mathrm{~nm}$ and C2 $471.72 \mathrm{~nm}$ signals as a function of the sample led to an apparent discrimination between $\mathrm{A}+\mathrm{C}$ on the one hand and $\mathrm{H}+\mathrm{P}$ on the other hand. In this experiment the helium buffer gas gave the opportunity to measure $\mathrm{CN}$ signal only when the plastic is containing a $\mathrm{CN}$ bond. The $\mathrm{CN}$ signal is high for the plastic A containing acrylonitryle, (Table 1) while it is lower for $C$ containing a lower proportion of acrylonitrile. The only difference between $\mathrm{A}$ and $\mathrm{C}$ is the presence of polycarbonate in the C plastic, so it is logical to obtain a similar C2 signature and a different intensity of the $\mathrm{CN}$ band. This result differs from the conclusions of Grégoire et al. [18] as they measured a similar C2 signal for all the aromatic polymers including polystyrene and ABS. The LIBS system employed is very similar apart from the helium buffer gas. In our experiment, Polypropylene (P) and HiPS gave extremely low signals for $\mathrm{CN}$ as they do not contain nitrogen. Although a helium buffer was also employed when a higher energy and laser wavelength were employed for the same experiment, no discrimination could be observed. In our study, the $266 \mathrm{~nm}$ laser gave best results for plastic discrimination under a helium atmosphere.

Calculation of the ratios $\mathrm{CN} / \mathrm{He}$ and $\mathrm{C} 2 / \mathrm{He}$ could provide the discriminant measurements required to sort the plastic sample evaluated in this study. The plot of [C2 $471.72 \mathrm{~nm} / \mathrm{He}$ I $667.815 \mathrm{~nm}$ ] against [CN $388.34 \mathrm{~nm} / \mathrm{He}$ I $667.815 \mathrm{~nm}$ ] exhibited a discrimination of the samples as four distinct groups (Fig. 6). The uncertainty of the ratio measurements were ranging in the 15 to $20 \%$, allowing to significantly distinguished the four groups corresponding to: A (ABS), C (ABS-PC), H (HiPS) and P (PP). Using similar emissions, Sattman [28] identified polymers with C2 $516.52 \mathrm{~nm}$ emission and a [C I $247.856 \mathrm{~nm} / \mathrm{H} \mathrm{I} 486.135 \mathrm{~nm}$ ] ratio, while Anzano [13] employed the [H I $656.271 \mathrm{~nm} / \mathrm{C}$ I $247.856 \mathrm{~nm}$ ] and [C2 $516.52 \mathrm{~nm} / \mathrm{C}$ I $247.856 \mathrm{~nm}$ ] intensity ratios. The present work demonstrated that plastic sorting using CN $388.34 \mathrm{~nm}, \mathrm{C} 2471.72 \mathrm{~nm}$ and He I $667.815 \mathrm{~nm}$ signals, available when using a helium atmosphere, could remarkably improve discrimination.

\section{Conclusion}

A detailed evaluation of the LIBS signals of plastic sample using different plasma conditions was made. The element identification in different plastic matrices was possible using 266 or $532 \mathrm{~nm}$ lasers. The comparison of a helium atmosphere and an air atmosphere led to improved results using helium as a buffer gas. The improvement is obtained in two areas, it increases the detection of halogens $(\mathrm{Br}, \mathrm{Cl})$ usually employed as flame retardants for plastics. Even if the signal does not improved for all the elements, due to specific objective i.e. detecting flame retardants in plastics, the buffer gas is preferred. It also increased the discrimination capacity of the system. On the one hand, matrix effects are reinforced but on the other hand, the significant differences obtained for $\mathrm{C} 2 / \mathrm{He}$ and $\mathrm{CN} / \mathrm{He}$ ratios allowed discriminating the different plastics.

A quantification of the plastic additives ( $\mathrm{P}, \mathrm{Ca}, \mathrm{Cl}, \mathrm{Br}$ and $\mathrm{Sb}$ ) was made. When considering the different plasma conditions employed, a strong matrix effect was observed with the $266 \mathrm{~nm}$ laser and the helium buffer gas compared to the $532 \mathrm{~nm}$ laser employed with the same helium buffer but with a higher energy. The similar element 


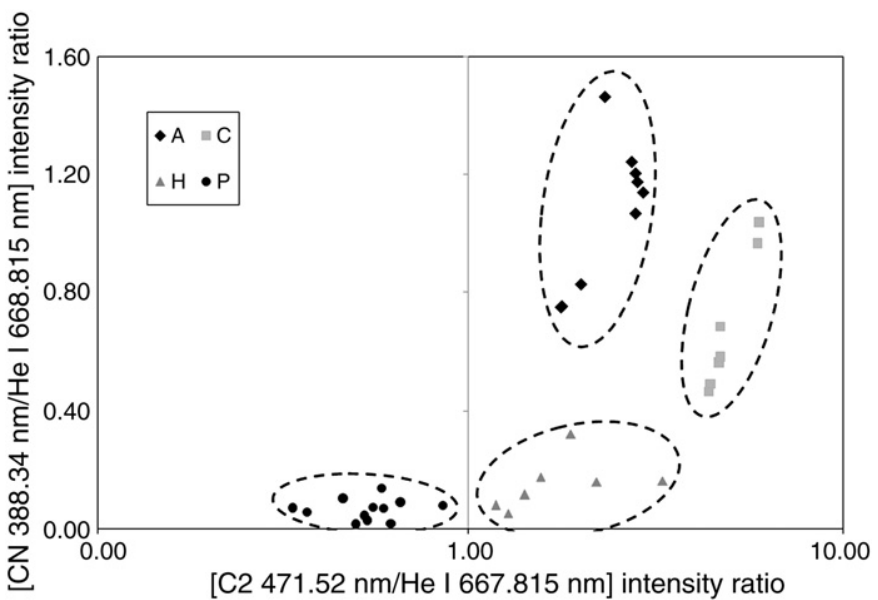

Fig. 6. Ratio plots, [C2 $471.72 \mathrm{~nm} / \mathrm{He}$ I $667.815 \mathrm{~nm}$ ] against [CN $388.34 \mathrm{~nm} / \mathrm{He}$ I $667.815 \mathrm{~nm}$ ]. Identified groups (dotted lines) correspond to the nature of the plastic: A, H, C and P. Measurement conditions are the same as mentioned in Fig. 5.

response obtained in the last configuration led to a better trueness when determination of the element content in a specific matrix is required. As the main objective for plastic sorting is the identification of the presence of an element with a fair quantification UV laser could be preferred.

Even if the conditions selected are more difficult to obtain for on-line sorting the reliability of the polymer sorting was improved, this work will be continued including real plastic sample and polymers that were not available for this study (PTFE, PA, PVC ...).

\section{Acknowledgments}

This work was performed in the frame of the global project TRIPLE (FUI-Fund). Labeled by the cluster Axelera, Triple gathers industrial and academic partners: the EFS technologies, the Armines, the Suez (environnement) -Sita group, the ARTS (association de recherche Technologie et Sciences), the Pelenc Society, the MTB Recycling group, and the BRGM (Bureau de recherche geologique et minier). It is supported by the French state, the urban communities of Lyon (Grand-Lyon), the Region Rhone-Alpes and the European Regional Development Fund (ERDF) of the European Union.

\section{References}

[1] G. De Sena, C. Nardi, A. Cenedese, F. La Marca, P. Massacci, M. Moroni, The hydraulic separator Multidune: preliminary tests on fluid-dynamic features and plastic separation feasibility, Waste Manage. 28 (2008) 1560-1571.

[2] S. Pongstabodee, N. Kunachitpimol, S. Damronglerd, Combination of three-stage sink-float method and selective flotation technique for separation of mixed post-consumer plastic waste, Waste Manage. 28 (2008) 475-483.

[3] L. St-Onge, R. Sing, S. Bechard, M. Sabsabi, Carbon emissions following $1.064 \mu \mathrm{m}$ laser ablation of graphite and organic samples in ambient air, Appl. Phys. A: Mater. 69 (1999) S913-S916.

[4] M. Boueri, M. Baudelet, J. Yu, X.L. Mao, S.S. Mao, R. Russo, Early stage expansion and time-resolved spectral emission of laser-induced plasma from polymer Appl. Surf. Sci. 255 (2009) 9566-9571.

[5] F.O. Leme, Q. Godoi, P.H.M. Kiyataka, D. Santos, J.A.M. Agnelli, F.J. Krug, Effect of pulse repetition rate and number of pulses in the analysis of polypropylene and high density polyethylene by nanoseconds Infra-Red laser induced breakdown spectroscopy, Appl. Surf. Sci. 258 (2012) 3598-3603.

[6] Anzano, R.-J. Lasheras, B. Bonilla, Classification of polymers by determining of C-1:C-2:CN:H:N:O ratios by laser-induced plasma spectroscopy (LIPS), Polym. Test. 27 (2008) 705-2008.

[7] J. Jasik, J. Heitz, J.D. Pedarnig, P. Veis, Vacuum ultraviolet laser-induced breakdown spectroscopy analysis of polymers, Spectrochim. Acta B 64 (2009) 1128-1134.

[8] I. Radivojevic, R. Niessnera, C. Haisch, S. Florek, H. Becker-Ross, U. Panne, Detection of bromine in thermoplasts from consumer electronics by laser-induced plasma spectroscopy, Spectrochim. Acta B 59 (2004) 335-343.

[9] R. Viskup, B. Praher, T. Linsmeyer, H. Scherndl, J.D. Pedarnig, J. Heitz, Influence of pulse-to-pulse delay for $532 \mathrm{~nm}$ double-pulse laser-induced breakdown spectroscopy of technical polymers, Spectrochim. Acta B 65 (2010) 935-2010.

[10] J. Anzano, M.E. Casanova, M.S. Bermudez, R.J. Lasheras, Rapid characterisation of plastics using laser-induced plasma spectroscopy (LIPS), Polym. Test. 25 (2006) 623-627.

[11] M. Tran, S. Sun, B.W. Smith, J.D. Winefordner, Determination of C:H:O:N ratios in solid organic compounds by laser-induced plasma spectroscopy, J. Anal. Atom. Spectrom. 16 (2001) 628-632.

[12] C.A. Munson, F.C. De Lucia, T. Piehler, K.L. McNesby, A.W. Miziolek, Investigation of statistics strategies for improving the discriminating power of laser-induced breakdown spectroscopy for chemical and biological warfare agent stimulants, Spectrochim. Acta B 60 (2005) 1217-1224.

[13] J. Anzano, B. Bonilla, B. Montull-Ibor, J. Casas-Gonzalez, Plastic identification and comparison by multivariate techniques with laser-induced breakdown spectroscopy, J. Appl. Polym. Sci. 121 (2011) 2710-2716.

[14] R.J. Lasheras, C. Bello-Galvez, J. Anzano, Identification of polymers by libs using methods of correlation and normalized coordinates, Polym. Test. 29 (2010) 1057-1064.

[15] Q. Godoi, F.O. Leme, L.C. Trevizan, E.R. Pereira, I.A. Rufini, D. Santos Jr., F.J. Krug, Laser-induced breakdown spectroscopy and chemometrics for classification of toys relying on toxic elements, Spectrochim. Acta B 66 (2011) 138-143.

[16] Q. Godoi, D. Santos Jr., L.C. Nunes, F.O. Leme, I.A. Rufini, J.A.M. Agnelli, L.C. Trevizan, F.J. Krug, Preliminary studies of laser-induced breakdown spectrometry for the determination of Ba, Cd, Cr and Pb in toys, Spectrochim. Acta B 64 (2009) 573-581.

[17] M. Boueri, V. Motto-Ros, W.Q. Lei, Q.L. Ma, L.J. Zheng, H.P. Zeng, J. Yu, Identification of polymer materials using laser-induced breakdown spectroscopy combined with artificial neural networks, Appl. Spectrosc. 65 (2011) 307-314.

[18] S. Gregoire, M. Boudinet, F. Pelascini, F. Surma, V. Detalle, Y. Holl, Laser-induced breakdown spectroscopy for polymer identification, Anal. Bioanal. Chem. 400 (2011) 3331-3340.

[19] Ivea, http://www.ivea-solution.com May 2013.

[20] J.A. Aguilera, J. Bengoechea, C. Aragon, Spatial characterization of laser induced plasmas obtained in air and argon with different laser focusing distance, Spectrochim. Acta B 59 (2004) 461-469.

[21] J.A. Aguilera, C. Aragon, A comparison of the temperatures and electron densities of laser-produced plasmas obtained in air, argon and helium at atmospheric pressure, Appl. Phys. A Suppl. 69 (1999) S475-S478.

[22] G. Asimellis, S. Hamilton, A. Giannoudakos, M. Kompitsas, Controlled inert gas environment for enhanced chlorine and fluorine detection in the visible and near-infrared by laser-induced breakdown spectroscopy, Spectrochim. Acta B 60 (2005) 1132-1139.

[23] W. Sdorra, K. Niemax, Basic investigations for laser microanalysis: III. Application of different buffer gases for laser-produced sample plumes, Microchim. Acta 107 (1992) 319-327.

[24] N. Gilon, J. El-Haddad, A. Stankova, W.Q. Lei, Q.L. Ma, V. Motto-Ros, J. Yu, A matrix effect and accuracy evaluation for the determination of elements in milk powder by LIBS and laser ablation/ICP-OES spectrometry, Anal. Bioanal. Chem. 401 (2011) 2681-2689.

[25] W.Q. Lei, J. El Haddad, V. Motto-Ros, N. Gilon-Delepine, A. Stankova, Q.L. Ma, X.S. Bai, L.J. Zheng, H.P. Zeng, J. Yu, Comparative measurements of mineral elements in milk powders with laser-induced breakdown spectroscopy and inductively coupled plasma atomic emission spectroscopy, Anal. Bioanal. Chem. 400 (2011) 3303-3313.

[26] P. Lucena, A. Dona, L.M. Tobaria, J.J. Laserna, New challenges and insights in the detection and spectral identification of organic explosives by laser induced breakdown spectroscopy, Spectrochim. Acta B 66 (2011) 12-20.

[27] R.W.B. Pearse, A.G. Gaydon, The Identification of Molecular Spectra, fourth ed. Chapman and Hall, New York, 1976.

[28] R. Sattmann, I. Monch, H. Krause, R. Noll, S. Couris, A. Hatziapostolou, A. Mavromanolakis, C. Fotakis, E. Larrauri, R. Miguel, Laser-induced breakdown spectroscopy for polymer identification, Appl. Spectrosc. 52 (1998) 456-461. 